\title{
Cardiac tamponade in rheumatoid arthritis
}

\author{
PEDRo SÁNCHEZ-GARCÍA \\ M.D. \\ PEDRO PAVÓN-OSUNA \\ M.D. \\ JAVIER DEL PINO-MONTES \\ M.D.
}

MIGUEL CORDERO-SÁNCHEZ

M.D.

ANTONIO ARRIBAS-JIMÉNEZ

M.D.

José De PoRTUGAL-ÁlVAREZ

M.D.

Department of Internal Medicine and Service of Cardiology, University Hospital, Salamanca, Spain

\begin{abstract}
Summary
A 56-year-old woman with definite rheumatoid arthritis developed cardiac tamponade while her disease was both clinically and serologically inactive. To our knowledge such a complication has been reported only once previously.
\end{abstract}

KEY WORDS: pleural effusion, prednisolone, echocardiography.

\section{Introduction}

Although $40-50 \%$ of patients with rheumatoid arthritis show evidence of pericarditis on postmortem examination or by means of echocardiography, a very low incidence of pericarditis can be detected clinically (Bonfiglio and Atwater, 1969; Franco, Levine and Hall, 1972; Thadani, Iveson and Wright, 1975; Bacon and Gibson, 1972).

We recently saw a patient with definite rheumatoid arthritis in whom cardiac tamponade suddenly developed when her disease was clinically inactive and serologically negative. To our knowledge a serious pericardial complication with inactive rheumatic disease has been described only once previously (Grivaux et al., 1979).

\section{Case report}

A 56-year-old woman came with a 1-year history of arthralgia with swelling and morning stiffness in both wrists and metacarpophalangeal joints. Physical examination showed swelling in both wrists and metacarpophalangeal joints with motion tenderness affecting all of them. Blood pressure was 140/80 $\mathrm{mmHg}$. Investigations: erythrocyte sedimentation rate (ESR) $48 \mathrm{~mm} / \mathrm{hr}$ (Westergren method). Latex test was ++ , Waaler-Rose $1 / 160$ and antinuclear antibodies were positive to a dilution of $1 / 640$ with speckled pattern. The LE phenomenon and antiDNA antibodies (Chritidia lucillae test) were nega- $\smile$ tive. Radiological examination of the chest was normal. In both hands, subcondral osteoporosis, soft $\vec{\bullet}$ tissue swelling and cortical erosions were detected.

One month after the diagnosis of definite rheumatoid arthritis, stiffness, swelling and tenderness devel-o oped in the left ankle. Chrysotherapy was begun and this treatment was continued until a dosage of $1 \mathrm{~g}$ was reached, with clinical remission and improvement in the laboratory tests 1 month before the end of the 0 course.

Ten months after diagnosis and $2 \frac{1}{2}$ months after 3 the course of chrysotherapy she became suddenly dyspnoeic. On examination blood pressure was $80 / 550$ $\mathrm{mmHg}$, respirations $36 / \mathrm{min}$ and heart rate $120 / \mathrm{min}$. 흥 Jugular veins were full without discernible pulse at $\underline{3}$. $45^{\circ}$. Neither Kussmaul's sign nor pulsus paradoxus were observed. Cardiac examination showed diminished heart sounds without murmurs or rubs. A chest $\bigcirc$ $\mathrm{X}$-ray (Fig. 1) revealed right pleural effusion and $\mathrm{a}$ huge cardiac silhouette. The electrocardiogram $ᄋ$ showed sinus tachycardia and diminished amplitude $>$ with non-specific ST-T changes. Central venous pressure was $24 \mathrm{~cm} \mathrm{H}_{2} \mathrm{O}$. An echocardiogram re- N vealed grade IV pericardial effusion.

Pericardiocentesis yielded $600 \mathrm{ml}$ of serofibrinous $\tilde{O}$ fluid and the patient improved rapidly. A drainage ${ }_{\omega}^{N}$ tube was left in the pericardial cavity obtaining 1200 O $\mathrm{ml}$ of fluid in $\mathbf{4 8} \mathrm{hr}$. Cardiomegaly and echocardiog raphic abnormalities disappeared and the patient ${ }_{\mathscr{D}}^{\circ}$ became asymptomatic. Investigations showed nor- - ? mochromic normocytic anaemia with haemoglobin 0 of $11.2 \mathrm{~g} / \mathrm{dl}$, with normal ESR and negative latex test; the pericardial fluid showed $55 \times 10^{6} / 1$ leucocytes with $89 \%$ granulocytes, a glucose level below $10 \stackrel{\widetilde{\Phi}}{\circ}$ $\mathrm{mg} / \mathrm{dl}$, 


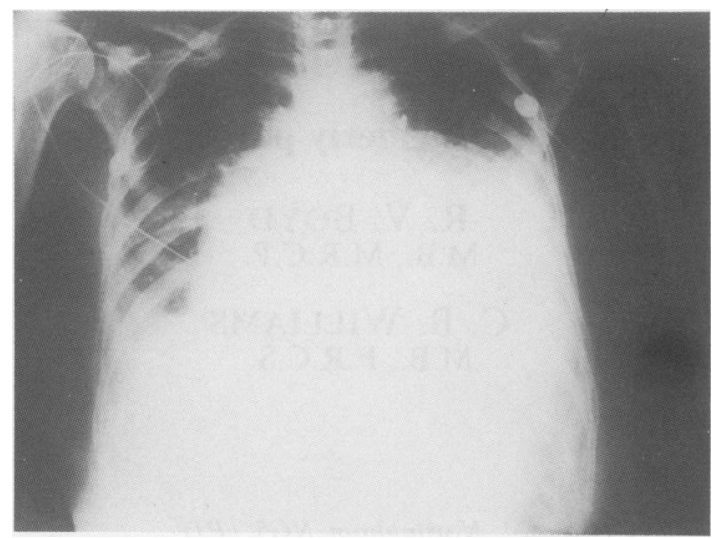

FIG. 1. Chest $\mathrm{X}$-ray revealing huge cardiomegaly and right pleural effusion.

negative latex and Waaler-Rose tests, absence of acid-fast bacilli and negative Gram stain. Cultures were negative and cytological examination did not show abnormal cells. After general and intrapericardial methylprednisolone therapy during the acute episode, prednisone $(60 \mathrm{mg} /$ day p.o.) was administered for 2 weeks. Tapering of the dose was then begun as the patient remained asymptomatic. Five months after the pericardiocentesis she remains asymptomatic both from the articular and pericardial disease on a prednisone dosage of $5 \mathrm{mg} /$ day. Rheumatoid factor is negative and ESR and gammaglobulin level are within normal range but antinuclear antibodies are still positive at $1 / 40$ dilution.

\section{Discussion}

Pericardial involvement has been detected in a high percentage of rheumatoid patients in necropsy and echocardiographic studies, but neither cardiac tamponade nor constrictive pericarditis are common complications of the disease (Nomeir et al., 1973). The rapid development of serious pericardial disease, as in our case, is even less frequent (John, Hough and Sergent, 1979). When the pericardium is affected clinically in the course of rheumatoid arthritis, rheumatoid factor is positive in $95 \%$ of the cases and subcutaneous nodules are found in $35 \%$ of the patients (Franco et al., 1972). In our case, however, subcutaneous nodules were never present and when the cardiac tamponade developed her rheumatoid factor was negative and the disease was clinically inactive, a situation not previously reported to our knowledge although Grivaux et al. (1979) described a patient with constrictive pericarditis in inactive rheumatoid disease. Although the probability was thus high that the exudative pericarditis was independent of her rheumatoid arthritis, the characteristics of the pericardial exudate were highly suggestive of a rheumatoid effusion: pleocytosis of neutrophils, an extremely low glucose level and negative microbiological and cytological examinations. We are not aware of follow-up studies on pericardial rheumatoid disease; our patient has done well with corticosteroids but the ultimate prognosis of this complication remains to be established.

This case stresses the systemic nature of the rheumatoid disease and the possibility of the appearance of organ involvement even when the process seems to be inactive.

\section{References}

BACON, P.A. \& GibSON, D.G. (1972) Cardiac involvement in rheumatoid arthritis. An echocardiographic study. Annals of the Rheumatic Diseases, 31, 426.

BONFIGLIO, T. \& ATWATER, E. (1969) Heart disease in patients with seropositive rheumatoid arthritis. A controhled autopsy study and review. Archives of Internal Medicine, 124, 714.

Franco, A.E., LeVINE, H.D. \& Hall, A.P. (1972) Rheumatoid pericarditis. Report of 17 cases diagnosed clinically. Annals of Internal Medicine, 77, 837.

GrivauX, M., Massias, P., Soulié, J., Hourdebaigt-Larruse, P. \& Guérinon, J. (1979) Péricardite constrictive complicant une polyarthrite rheumatoide biologiquement stabilisée. Annales de Médecine Interne, 130, 247.

John, J.T., Hough, A. \& SERGENT, J.S. (1979) Pericardial disease in rheumatoid arthritis. American Journal of Medicine, 66, 385.

Nomeir, A.M., TURNER, R., WATtS, E., Smith, D., WeSt, G. \& EDMONDS, J. (1973) Cardiac involvement in rheumatoid arthritis. Annals of Internal Medicine, 79, 800.

ThADANI, U., IVESON, J.M.I. \& WRIGHT, V. (1975) Cardiac tamponade, constrictive pericarditis and pericardial resection in rheumatoid arthritis. Medicine, 54, 261.

(Accepted 24 May 1983) 